Document downloaded from:

http://hdl.handle.net/10251/146884

This paper must be cited as:

Rocamonde, B.; Paradells, S.; Garcia Esparza, MA.; Sanchez Vives, M.; Sauro, S.; Martínez-Ramos, C.; Monleón Pradas, M.... (2016). Combined application of polyacrylate scaffold and lipoic acid treatment promotes neural tissue reparation after brain injury. Brain Injury. 30(2):208-216. https://doi.org/10.3109/02699052.2015.1091505

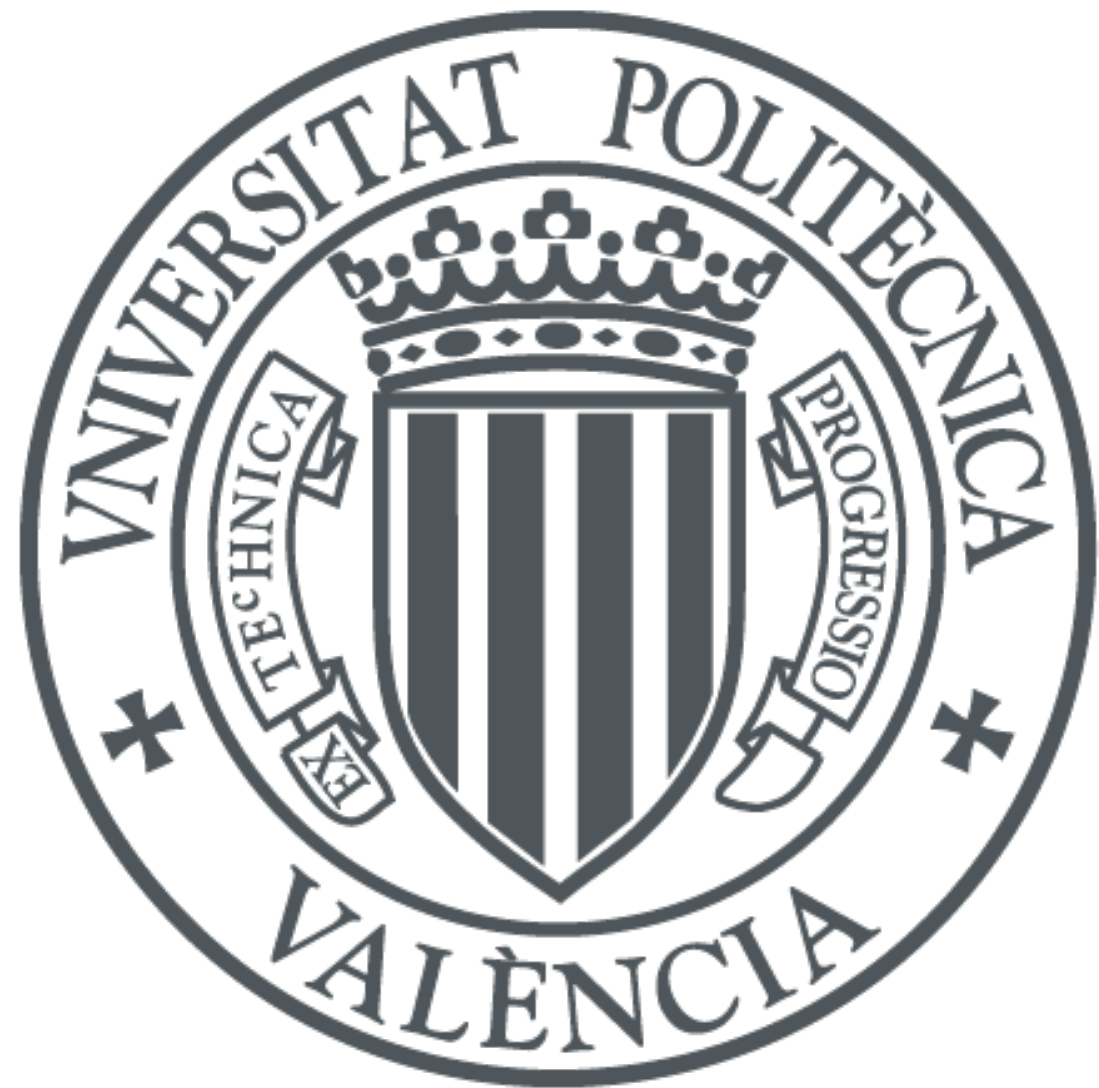

The final publication is available at

http://dx.doi.org/10.3109/02699052.2015.1091505

Copyright Taylor \& Francis

Additional Information 


\section{Combined application of polyacrylate scaffold and lipoic acid treatment promote neural tissue reparation after brain injury.}

Brenda Rocamonde ${ }^{\mathrm{a}}$, Sara Paradells ${ }^{\mathrm{a}}, \mathrm{M}^{\mathrm{a}}$ Angeles Garcia Esparza ${ }^{\mathrm{a}}$, Mavi Sánchez Vives ${ }^{\mathrm{b}}$, Salvatore Sauro $^{\mathrm{a}}$, Cristina Martínez Ramos ${ }^{\mathrm{c}}$, Manuel Monleón Pradas $^{\mathrm{c}}$ and José Miguel Soria ${ }^{\mathrm{a}, \mathrm{d}}$

\footnotetext{
${ }^{\text {a }}$ Facultad Ciencias de la Salud, Universidad CEU-Cardenal Herrera, Valencia, Spain.

${ }^{\mathrm{b}}$ Institut D’Investigacions Biomèdiques August Pi i Sunyer-IDIBAPS, Barcelona, Spain.

${ }^{\mathrm{c}}$ Centro de Biomateriales e Ingeniería Tisular, Universidad Politécnica de Valencia, Valencia, Spain.

${ }^{\mathrm{d}}$ Instituto de Ciencias Biomédicas, Universidad CEU-Cardenal Herrera, Moncada, Valencia, Spain.
}

\section{Corresponding author:}

José Miguel Soria, PhD

jose.soria@uch.ceu.es

Departamento de Ciéncias Biomédicas

Facultad Ciencias de la Salud, Universidad CEU- Cardenal Herrera

Avenida del Seminario s/n, Moncada 46313 (Valencia), España

Tel: +34961369000 Ext. 1353

Fax: +34961395272 


\section{ABSTRACT}

Traumatic brain injury is a multifarious damage with a broad spectrum of symptoms and disabilities. Due to the limited capacity of the central nervous system to repair traumatic injuries and the secondary cascade of insults that lead to worsened neurologic dysfunction, nowadays no treatment is able to effectively restore brain tissue. Research has been focusing on the stimulation of endogenous neural stem cells to viably and functionally repopulates the injured parenchyma as possible treatment for brain injury. Lipoic acid (LA) has been demonstrated being a potent antioxidant promoting neuro-regeneration and angiogenesis. Thus, the aim of this study was to develop and assesses the reparative potential of a polymeric scaffold designed for brain tissue repair in combination with lipoic acid.

Adult Wistar rats were subjected to cryogenic traumatic brain injury. A channelled-porous scaffold was created using a copolymer of ethyl acrylate and hydroxyethylacrylate, p(EA-coHEA). This was grafted into cerebral penumbra alone or combined with intraperitoneal LA administration as a new regenerative strategy. Histological and cytological evaluation was performed after 15 and 60 days and structural magnetic resonance (MRI) assessment was also performed at 2 and 6 months after the surgery. The results obtained suggest that this strategy promotes neuron migration and new blood vessels formation. The scaffold resulted colonised by a high number of mature cells and decreased microglial response, in particular when administrated with LA.

These evidences demonstrated that the combination of a channelled polymer scaffold with a pharmacological treatment using LA may represent a potential treatment for neural tissue repair after brain injury.

Keywords: Brain injury; Biopolymers; Lipoic acid; Oxidative stress; Neural repairing. 


\section{INTRODUCTION}

Traumatic brain injury (TBI) is a serious health problem around the world [1]. A significant number of patients with TBI survive with considerable brain damage and behavioural disability, even after mild or moderate brain injury [2-5]. Subsequent to primary injury, a neuroinflammatory response characterised by the release of reactive oxygen species (ROSs) from neutrophils are responsible for a secondary deleterious phenomena [6-8] due to increase of local oxidative stress and consequent cells death [9-12]. In our previous studies, it was shown how systemic administration of antioxidants, such as lipoic acid (LA), favours healing brain processes. In this sense, we observed that LA was able to recover the damaged tissue after brain injury model in rats via increasing the antioxidant aptitude of the tissue, promote angiogenesis and decrease the glial response $[13,14]$.

During the last decade, the use of bioactive materials with regenerative aptitude has been extensively adopted in the field of biomedicine $[15,16]$. Moreover, the application of natural and synthetic biopolymers has been widely used in clinical and experimental cases such as wound healing, drug delivery systems, vascular grafts and or tissue regeneration $[17,18]$.

Recently, different biogenic matrices have been developed as biocompatible/bioinductive scaffolds able to create a favourable environment for the regeneration of the nervous system and in particular for neural cells; the fibronectin as well as collagen matrices have been shown to promote nerve regeneration [19-22].

However, synthetic polymers have been proposed as a suitable alternative choice to natural molecules due to their versatility. Indeed, polymers can be developed with a wide variety of compounds (e.g. polystyrene, nylon, fibrinogen, collagen, hydrogels.) and they can be modified to achieve distinct physic-chemical and biomimetic properties [17, 18, 23, 24]. 
Soria and collaborators [24] have previously shown in vitro how biopolymers based on a combination of ethyl acrylate (EA) and hydroxyethylacrylate (HEA) may represent a suitable substrate for proliferation and differentiation of rodent NSCs [23, 25]; these were also tested for neuro-regenerative purposes in the CNS showing promising results [25].

We hypothesize that the administration of lipoic acid in combination with the p(EA-co-HEA) scaffold after brain injury can increase the neuroregenerative capacity of the tissue. There is no previous study on the neuro-regenerative ability of a scaffold of p(EA-co-HEA) when applied in combination with systemic administration of lipoic acid. Thus, this study aimed at developing and assesses the reparative potential of a polymeric $\mathrm{p}$ (EA-co-HEA) scaffold designed for brain tissue repair in rats treated with systemic therapy with lipoic acid.

\section{MATERIALS AND METHODS}

\subsection{Substrate material preparation}

Scaffolds were prepared following a porogen-template leaching method, as described in [2527]. The porous structure was generated with a template of sintered Nylon fabrics (Saati SA, Barcelona, Spain) of nominal thread diameter of 80 microns and mesh opening of 120 microns, which was afterwards eliminated by dissolution. The polymer matrix was a copolymer of ethyl acrylate (EA, 99\% pure, Sigma-Aldrich, Spain) and hydroxyethyl acrylate (HEA, 99\% pure, Sigma-Aldrich,) with EA:HEA mass ratio of 9:1, cross-linked into a network with ethyleneglycol dimethacrylate (EGDMA, 98\% pure, Sigma-Aldrich) in a mass ratio of $($ EA+HEA):EGDMA = 99:1. Azo-bis-isobutyronitrile (AIBN, 98\% pure. Merck) was also added (0.01 wt $\%)$ to act as thermal initiator of the polymerization. The polymerization was carried out for $24 \mathrm{~h}$ at $60^{\circ} \mathrm{C}$, and for $24 \mathrm{~h}$ more at $90^{\circ} \mathrm{C}$ in specific moulds $(5 \times 10 \mathrm{~cm})$. Subsequent to the polymerisation reaction, 
all the templates were dissolved by washing in nitric acid (65\%, Scharlab, Spain) under gentle shaking for $48 \mathrm{~h}$. Finally, the obtained materials were washed in boiling ethanol for $40 \mathrm{~h}$, and dried $24 \mathrm{~h}$ at room temperature, a further $24 \mathrm{~h}$ under vacuum and room temperature, and $24 \mathrm{~h}$ more under vacuum at $60^{\circ} \mathrm{C}$. Beams of approximately $1 \mathrm{~mm}$ thick and with a length of $4 \mathrm{~mm}$ were cut with a stainless steel blade (Procter \& Gamble, USA) and used in the experiments. All samples were sterilized with a $25 \mathrm{kGy}$ dose of gamma irradiation in a ${ }^{60} \mathrm{Co}$ source.

\subsection{Surgery and brain cryo-injury}

Adult male Wistar rats weighing $250 \pm 25 \mathrm{~g}$ were purchased from Harlan (Italy) one week before starting the experiment. Rats were maintained in controlled conditions at temperature of $\left(20^{\circ} \mathrm{C}\right)$ and humidity of $(60 \%)$. They also received constant light-dark cycles of 12 hours and feed with water and food ad libitum. Handling and care of animals were done according to the "Real Decreto" 1201/05, supervised and approved by the Committee of Ethics and Experimental Procedures of the Universidad CEU-Cardenal Herrera. Rats were anesthetised by intraperitoneal injection (i.p.) with a mixture consisting of $12 \mathrm{mg} / \mathrm{kg}$ ketamine, (Imalgene, Leonvet, Spain), 0.4 $\mathrm{mg} / \mathrm{kg}$ acepromizine, (Calmo Neosan, Pfizer, Spain) and $0.02 \mathrm{mg} / \mathrm{kg}$ phentanil (Baxtel, USA) and then placed in a stereotaxic frame. The dorsal part of the skull was exposed and a hole was drilled (1.5 $\mathrm{mm} \varnothing)$ on stereotaxic coordinates [28] antero-posterior: $0 \mathrm{~mm}$ from bregma and lateral: 1.5 $\mathrm{mm}$ from medial line. The brain cryo-injury was performed following the protocol described by Quintana et al., [28]. Thus, the cryo-injury (4 $\mathrm{mm}$ deep) was performed in the cerebral cortex by using a stainless steel probe $\left(1 \mathrm{~mm}\right.$ of diameter) previously frozen in liquid nitrogen $\left(-196^{\circ} \mathrm{C}\right)$. Buprenorphine $(0.05 \mathrm{mg} / \mathrm{kg}$, subcutaneously) was administered postoperatively and the rats were placed on heating pads at $37^{\circ} \mathrm{C}$ and monitored continuously for $2 \mathrm{~h}$ after surgery. In addition, immediately after surgery, all subjects received $3 \%$ body weight of $0.9 \%$ saline subcutaneously to prevent dehydration. 


\subsection{Lipoic acid administration}

Cryo-injured rats were randomly selected immediately after surgery. The first group (BM+LA) of samples $(\mathrm{N}=28)$ received a daily intraperitoneal (i.p.) dose of lipoic acid $100 \mathrm{mg} / \mathrm{kg}(\mathrm{LA})$ (Sigma Aldrich) for 7 days starting the same day of surgery. The second group (BM) of samples $(\mathrm{N}=28)$ received the same volume of saline $(\mathrm{NaCl} 0.9 \%$ i.p.) for the same period of time. Control group consisted of animals that received no brain injury, kept under the same conditions of anaesthesia for the same period of time as in the experimental groups, but with no i.p. injection.

\subsection{Tissue preparation and experimental design}

Animals were sacrificed by using an overdose of sodium pentobarbital (Dolethal, Vetoquinol S.A.) via i.p. injection. Once sacrificed, animals were transcardially perfused with $100 \mathrm{~mL}$ of saline followed by $200 \mathrm{~mL}$ of $4 \%$ paraformaldehyde (PFA) (Sigma-Aldrich, Spain) in saline phosphate buffer (PBS) 0.01 M pH 7.2. Brains were removed and post fixed in the same fixative solution for $24 \mathrm{~h}$ at $4{ }^{\circ} \mathrm{C}$. Subsequently, all the extracted brains were cryo-protected by immersion in a PBS solution $0.01 \mathrm{M}$ of sucrose $(30 \% ; \mathrm{pH} 7.1)$ for five days at $4{ }^{\circ} \mathrm{C}$. Sections of $25 \mu \mathrm{m}$ thick were serially obtained with a cryostat (Leica) and mounted onto glass slides. Sections were stored at $-80{ }^{\circ} \mathrm{C}$ until use.

The experimental design of this study was to perform histological and cytological evaluation 15 and 60 days after the surgery ( $\mathrm{n}=8$ for each group). Moreover, an ultra-structural study was also carried out through magnetic resonance imaging (MRI) at 2 and 6 months after the surgery $(n=6$ for each group). 


\subsection{Histological staining and microscopy}

Haematoxylin-eosin staining was performed for histological assessment of the injured area and the insertion of the biomaterial. Sections were rinsed with PBS $0.01 \mathrm{M}$ for $5 \mathrm{~min}$, and then dehydrated with increasing ethanol for $3 \min \left(100^{\circ}, 96^{\circ}, 70^{\circ}, 50^{\circ}, 30^{\circ}\right)$ and finally rinsed with bi-distilled water for 3 min. After incubation in Harris haematoxylin (Sigma Aldrich, Spain) for 5 min, the specimens were washed with water and placed in $1 \% \mathrm{HCl}-\mathrm{EtOH} 70^{\circ}$ for $5 \mathrm{sec}$; they were rinsed with water for further $5 \mathrm{~min}$. Afterwards, these specimens were incubated in a $2 \%$ eosin aqueous solution (Sigma Aldrich, Spain) for 2 min, dehydrated with ethanol $96^{\circ}$ and $100^{\circ}$ and finally cover-slipped with Eukitt® (Sigma Aldrich). Digital images were acquired with a Nikon DS-Fi-1 digital camera (Barcelona, Spain) coupled to a Leica DM2000 Microscope at 5x, 20x, 40x and 63x magnifications.

\subsection{Immunofluorescence staining and confocal microscopy}

Further sections were obtained from the injury and rinsed three times using a 0.01 M PBS solution for $5 \mathrm{~min}$. The specimens were first immersed in $0.1 \%$ PBS-Triton containing $20 \%$ Foetal Bovine Serum (Gibco®, Life TechnologiesTM) for 2 hours and then incubated at $4{ }^{\circ} \mathrm{C}$ overnight with primary antibodies: anti-Collagen IV (1:200, Abcam, Spain); anti-Glial Fibrilar Acidic Protein [GFAP] (1:500, Dako Cytomation, Denmark), anti-CD68 [ED1] (1:200, Chemicon, UK), anti-Iba1 (1:200, Wako, German), anti-beta III tubulin [Tuj1] (1:200, Abcam, Spain) and antimicrotubule associated protein 2 [MAP2] (1:200, Millipore, Spain).

Secondary antibodies Alexa Fluor® 488 IgG $(\mathrm{H}+\mathrm{L})$ (1:200, Invitrogen, Spain) and Alexa Fluor® $555 \operatorname{IgG}(\mathrm{H}+\mathrm{L})$ (1:200, Invitrogen, Spain) were used for further $2 \mathrm{~h}$ of incubation at room temperature in the darkness. Afterwards, sections were mounted with DAPI Vectashield (Vector Laboratories, UK) and image-processed using a Leica DM2000 Microscope at 5x magnification 
and a Nikon EZ-C1 in Ti-U Eclipse Inverted Confocal Microscope (Tokyo, Japan) using 40x and 63x oil objectives (Plan Apo, Nikon).

\subsection{Magnetic Resonance Imaging Study}

The structural study of animals was carried out through Magnetic Resonance Imaging (MRI) 7.0T-T BioSpec 70/30 horizontal scanner (Bruker BioSpin, Ettlingen, Germany), equipped with an actively shielded gradient system $(400 \mathrm{mT} / \mathrm{mm} 12 \mathrm{~cm}$ inner diameter). The receiver coil was a 4cannel phased-array surface coil for the rat brain. Animals were placed in supine position in a Plexiglas holder with a nose cone for administering anaesthetic gases $(1.5 \%$ isofluorane in a mixture of $30 \% \mathrm{O}_{2}$ and $70 \% \mathrm{CO}_{2}$ ) and were fixed using a tooth bar, ear bars and adhesive tape. Tripilot scans were used to ensure accurate positioning of the head in the isocenter of the magnet. Brain lesions were evaluated by $\mathrm{T} 2$ mapping of coronal slices acquired with a multislice-multiecho (MSME) sequence by applying 16 TEs, from 11 to $176 \mathrm{~ms}, \mathrm{TR}=4764 \mathrm{~ms}$, slice thickness = $1 \mathrm{~mm}$, number of slices $=18, \mathrm{FOV}=40 \times 40 \mathrm{~mm}$, and matrix size $=256 \times 256$ pixels, resulting in a spatial resolution of $0.156 \times 0.156 \mathrm{~mm}$ in $1.00 \mathrm{~mm}$ slice thickness. At the end of the procedure, the animals were removed from the platform ad and woken up with an i.p. injection $(1 \mathrm{mg} / \mathrm{kg})$ of atipamezole (Antisedan®, Pfizer, Spain).

\subsection{Quantification and Statistical Analysis}

Immunocytochemical images were analysed with Image J 1.44i for Mac. The quantifications were performed using four sections of each animal ( $\mathrm{n}=8$ for each group). Three images in each section were randomly acquired inside the biomaterial and quantified. The density of cells $\left(\mathrm{n}^{\mathrm{o}}\right.$ cells $\left./ \mathrm{mm}^{2}\right)$ was assessed by counting the number of nuclei (determined by DAPI staining) co-expressing the marker to analyse. The percentage of area occupied by astrocytes and blood vessels was also calculated as the area occupied by the corresponding marker referred to total area quantified. 
Images were converted to binary after thresholding and the area calculation was set in measurements.

The T2 maps images were reconstructed with ParaVision 5.03 software (Bruker BioSpin, Ettlingen, Germany) and analysed with the program ImageJ 1.44f for Mac to obtain the grey values inside the biomaterial tissue. To do so, images were assigned predetermined values (20130) and grey values were set in measurements.

To perform the statistical analyses of the data, GraphPad Prism 4 for Mac was used. Statistical significances were assessed by two-way ANOVA followed by Bonferronni post-test. Data are represented as means \pm standard deviation, and differences are considered significant at $\mathrm{p}<0.05$.

\section{RESULTS}

\subsection{Biocompatibility of the polymeric scaffold}

The biomaterial tested in this study was successfully implanted close to the LV as previously described (Fig. 1A). No immunological rejection was observed. Indeed a perfect biocompatibility with the surrounding tissue and a sound healthy interface between the brain tissue and the biomaterial were observed (Fig. 1B). In addition, the SVZ integrity was not perturbed by the insertion of the scaffold (Fig. 1C). One of the first remarkable findings was the presence of a high number of cells inside the biomaterial (Fig. 1D). Specifically, the animal specimens treated with LA presented greater cytoplasmic expansions (Fig. 2A). The cell population within the biomaterial, (Fig. 2B) showed no significant increase compared to the control group $(\mathrm{p}<0.001$ and $\mathrm{p}<0.01$ for $\mathrm{BM}$ and $\mathrm{BM}+\mathrm{LA}$ respectively) 15 days after brain injury. However at 60 days, the specimens treated with LA presented a cell density comparable to that of the control specimens. However, this increase in cell density was not observed in the specimens that were not treated with LA ( $p<0.001$ vs Control). 


\subsection{New blood vessels are generated inside the biomaterial}

The immunofluorescence study for blood vessels $\left(\right.$ Collagen $\left.\mathrm{IV}^{+}\right)$showed the presence of blood vessels formation inside the biomaterial (Fig. 3A) characterised by a correct morphology and functionality (Fig. 3B).

Concerning the quantification of the endothelial cell density (Fig. 3C) at 15 days, the animal specimens treated with LA presented a significant increase in the number of endothelial cells compared to non-treated animals $(\mathrm{p}<0.05)$. However, after 60 days the cell density was increased in both experimental groups $(\mathrm{p}<0.01)$.

Furthermore, the area occupied by blood vessels (Fig. 3D) in both experimental groups was comparable with control group at 15 days. However, an increase of area was found in both experimental groups at 60 days. Interestingly, LA-treated specimens showed a higher area compared to untreated specimens $(\mathrm{p}<0.01)$.

\subsection{Astrocytes grow inside the polymeric scaffold}

The immunofluorescences analysis of the astrocytes $\left(\mathrm{GFAP}^{+}\right.$cells) (Fig. 4A) showed a rare presence of astrocytes in untreated animals at 15 days, while the LA treated animals showed an ample growth of astrocytes inside the biomaterial. However, an abundant number of astrocytes was observed in both experimental groups at 60 days.

The quantitative analysis showed an increase in the density of $\mathrm{GFAP}^{+}$cells (Fig. 4B) only in LA treated animals compared to the control at both times $(\mathrm{p}<0.05$ at 15 days and $\mathrm{p}<0.01$ at 60 days). Conversely, the measurement of the area occupied by astrocytes (Fig. 4C) showed a statistical significant increase in LA treated group compared to the untreated group $(\mathrm{p}<0.001)$ and even more compare to the control group ( $\mathrm{p}<0.001)$ at 15 days. However, at 60 days, the area of astrocytes was increased in both experimental groups compared to the control specimens ( $\mathrm{p}<$ $0.01)$. 


\subsection{Presence of microglial cells}

The presence of microgial cells and their morphology are crucial for the determination of the inflammatory response. Therefore, the immunofluorescences analysis for microglia (Iba $1^{+}$cells) and activated microglia/macrophage $\left(\mathrm{ED} 1^{+}\right.$cells) highlighted a high number of microglial cells inside the biomaterial in both experimental groups at 15 days with a decrease at 60 days (Fig. 5). The quantification of the density of $\mathrm{Iba}^{+}$cells (Fig. 6A) showed a significant increase in both experimental groups compared to the control but not between experimental groups.

The quantification of activated microglia/macrophages (ED1 ${ }^{+}$cells) (Fig. 6B) showed a significant increase in both experimental groups compared to the control at all time points $(\mathrm{p}<$ 0.001). Interestingly, at 15 days, $\mathrm{ED} 1^{+}$cells showed a decrease in LA treated group compared to the untreated group $(\mathrm{p}<0.01)$.

Resting microglia, identified as Iba $1^{+} \mathrm{ED} 1^{-}$cells (Fig. 6C), showed a decrease at 60 days in Latreated group compared with the untreated group $(\mathrm{p}<0.001)$.

Infiltrated macrophages were identified as $\mathrm{Iba1}^{-} \mathrm{ED} 1^{+}$(Fig. 6D). An increase in infiltrated macrophages was found at all time points and specially in untreated animals at 60 days.

Activated microglia, identified by $\mathrm{Iba} 1^{+} \mathrm{ED} 1^{+}$cells (Fig. $6 \mathrm{E}$ ), was increased in a similar way to that observed with infiltrated macrophages. In addition, LA administration decreased activated microglia in a significant way compared with untreated group $(\mathrm{p}<0.05)$.

\subsection{Neuronal bodies and axons are found inside the biomaterial}

The presence of young neurons was identified by immunofluorescence for the marker Tuj1 (red) and MAP2 (green) was used in order to identify mature neurons (Fig. 8). Axons extending from the surrounding tissue into the biomaterial were observed 60 days after the brain injury (Fig. 7A). In addition, immature neurons (Tuj $1^{+}$cells) inside the biomaterial expressing as well the 
marker MAP2 were detected (Fig. 7B). Mature neurons (Fig. 7C) and their axons were visible inside the biomaterial (Fig. 8D).

Quantifications developed 60 days after the brain injury (Fig. 7E) showed an increase of immature neurons after LA treatment compared with untreated group $(\mathrm{p}<0.05)$. In addition, the density of mature neurons was significantly increased after LA treatment compared to untreated group ( $\mathrm{p}<0.001)$ and decreased in untreated animals compared with control group $(\mathrm{p}<0.001)$.

\subsection{MRI: quantification of the healthy neural tissue inside the biomaterial}

The structural analysis performed using magnetic resonance imaging shows the presence of liquid and the health state of the neural tissue that could be quantified in grey-scale values. T2 scans through MRI in untreated animals (Fig. 8A) and LA treated animals (Fig. 8B) were carried out at 2 and 6 months after brain injury. The quantification of the grey values inside the biomaterial (Fig. 8C) showed a significant decrease of grey values in both experimental groups (p $<0.001$ ) indicating a high presence of liquid inside the biomaterial. However, it was also observed a significant increase of grey values in LA-treated group compared untreated group $(p<0.001) 6$ months after brain injury; associated with tissue regeneration.

\section{DISCUSSION}

Brain injury is a devastating phenomenon with no effective treatment available for the time being. Due to the limited capacity of the brain to repair itself, the search of new neural repair strategies has been the goal standard in regenerative medicine in the last decades. The transplantation of rat or mouse stem/progenitor cells has been used recently in order to study the mechanisms of CNS regeneration. Some studies have reported that engrafted cells can survive in the host brain for up to a year [29, 30]. Nevertheless, in most of the cases only less than $2 \%$ of the transplanted cells engraft and additionally, most of the engrafted cells differentiate into glia, not 
neurons $[31,32]$. However, the brain also has endogenous NSCs located in the dentate gyrus and the subventricular zone $[33,34]$. Significant increases in cell proliferation and neurogenesis have been reported in the SVZ and DG in response to brain injury [35], suggesting that the brain has an inherent potential to restore itself. However this self-repair capacity is limited due to the exacerbated inflammatory response. Following traumatic brain injury, some studies have reported that several growth factors and drugs can enhance neurogenesis and improve functional recovery of the injured brain. For instance, it has been observed that administration of growth factors such as epidermal growth factor (EGF) or vascular endothelial growth factor (VEGF) -a potent angiogenic factor- can significantly enhance cell proliferation in the SVZ after trauma [36, 37]. An increase in angiogenesis has been observed when LA is combined with biomaterial application after brain injury. This result agrees with those previous reported by our group where systemic administration of LA can stimulate angiogenesis and proliferation after brain injury [14].

The use of polymer scaffolds has been recently developed and applied in central and peripheral nervous system as an attempt to favour cell support in regeneration. The development and design of synthetic extracellular matrix have been the main goal in tissue engineering in order to regulate cell behaviour and tissue progression in regeneration. The sought properties for nerve regeneration concerning biomaterials are less inflammatory response, adequate porosity for vascularization and cell migration, biocompatibility with the tissue and three-dimensional matrices with appropriate mechanical properties to mimic extracellular matrix [38, 39]. Previously in vitro studies developed by our group has shown these scaffolds based on $\mathrm{p}$ (EA-co-HEA) as a suitable substrates for proliferation and differentiation of rodent NSCs $[23,24]$. The recent findings exposed above now suggest that this polymeric scaffold can be used for brain tissue repair after brain injury in vivo, acting as a suitable substrate for cell growth.

After the primary brain injury, the secondary response including glial reaction promotes glial scar formation hinder tissue regeneration. We have previously reported a decrease in the glial scar 
formation and inflammation when LA was administered systemically after brain injury [13, 14]. In addition, the results obtained in this study suggest that the application of the p(EA-co-HEA) scaffold could be acting in the same way, reducing glial scarring and activated microglia through a decrease on inflammation. Similar results were obtained by Park et al. using a fibrous poly(glycolic acid) scaffold seeded with NSCs in a stroke model, showing that the cells were able to differentiate and reduce the inflammation and glial scarring [40]. An implant of a biomaterial based on poly(lactic-co-glycolic acid) (PLGA) and polylysine seeded with NSCs was used in a rat model of spinal cord injury [41]. The study showed an increase in the motor activity of the animals and a decrease in the glial scar formation. Interestingly, the improvements regarding the glial scar formation were attributed in part to the implant material itself.

Concluding, we have reported that combined application of p(EA-co-HEA) 90/10 scaffold and LA administration promotes cell colonization of the damaged area and tissue regeneration. A decrease of the glial scarring as well as an increase of angiogenesis has been observed, in addition to an increase of neurons inside the biomaterial. This results open new insights into the regeneration strategies after brain injury. However, future interventions may include other strategies -such as in situ controlled delivery of neuroprotective substances or growth factors- in order to optimize tissue repair.

\section{CONCLUSION}

The use of $\mathrm{p}$ (EA-co-HEA) 90/10 polymeric scaffold provides good support for the regeneration of damaged tissue after brain injury. The application of the polymeric scaffold together with a systemic LA administration increases the angiogenesis, decreases glial scaring, and favour neuronal migration into the biomaterial. These results represent a step forward in the regenerative strategy for brain injury. 


\section{ACKNOWLEDGMENTS}

JMSL acknowledges funding through Programa de Ayudas a la Investigación Científica Universidad CEU-Cardenal Herrera (PRCEU-UCH 34/12) and (PRCEU-UCH 38/10).

CMR and MMP acknowledge financing through projects MAT2011-28791-C03-02 and ERANET NEURON project PRI-PIMNEU-2011-1372.

\section{REFERENCES}

1. Das M, Mohapatra S, and Mohapatra SS. New perspectives on central and peripheral immune responses to acute traumatic brain injury. J Neuroinflammation, 2012. 9: p. 236.

2. Harrahill M. Management of severe head injury: new document provides guidelines. Brain Trauma Foundation. J Emerg Nurs, 1997. 23(3): p. 282-3.

3. Jennett B. Prognosis after severe head injury. Clin Neurosurg, 1972. 19: p. 200-7.

4. Kumar S, Rao SL, Chandramouli BA, and Pillai S. Reduced contribution of executive functions in impaired working memory performance in mild traumatic brain injury patients. Clin Neurol Neurosurg, 2013. 115(8): p. 1326-32.

5. Muehlschlegel S, Carandang R, Ouillette C, Hall W, Anderson F, and Goldberg R. Frequency and impact of intensive care unit complications on moderate-severe traumatic brain injury: early results of the Outcome Prognostication in Traumatic Brain Injury (OPTIMISM) Study. Neurocrit Care, 2013. 18(3): p. 318-31.

6. Demopoulos HB, Flamm ES, Pietronigro DD, and Seligman ML. The free radical pathology and the microcirculation in the major central nervous system disorders. Acta Physiol Scand Suppl, 1980. 492: p. 91-119.

7. Hall ED and Braughler JM. Central nervous system trauma and stroke. II. Physiological and pharmacological evidence for involvement of oxygen radicals and lipid peroxidation. Free Radic Biol Med, 1989. 6(3): p. 303-13.

8. Siesjo BK, Agardh $\mathrm{CD}$, and Bengtsson F. Free radicals and brain damage. Cerebrovasc Brain Metab Rev, 1989. 1(3): p. 165-211.

9. Yukido I and Long M. The molecular basic of brain injury and brain edema. The role of oxygen free radicals. Neurosurgery, 1990. 27: p. 9.

10. Kaur C and Ling EA. Antioxidants and neuroprotection in the adult and developing central nervous system. Curr Med Chem, 2008. 15(29): p. 3068-80.

11. MA H, JR K, and RJ T. Radical scavenegers: Penetration into brain following the ischemia and reperfusion, in Pharmacology of Cerebral Ischemia, Krieglstein J Oberpichler-Schwenk H, editors., Editor. 1994, Medpharma Scientific Publishers: Stuggart. p. 297-309.

12. Xia W, Han J, Huang G, and Ying W. Inflammation in ischaemic brain injury: current advances and future perspectives. Clin Exp Pharmacol Physiol, 2010. 37(2): p. 2538. 
13. Rocamonde B, Paradells S, Barcia C, Garcia Esparza A, and Soria JM. Lipoic acid treatment after brain injury: study of the glial reaction. Clin Dev Immunol, 2013. 2013: p. 521939.

14. Rocamonde B, Paradells S, Barcia JM, Barcia C, Garcia Verdugo JM, Miranda M, Romero Gomez FJ, and Soria JM. Neuroprotection of lipoic acid treatment promotes angiogenesis and reduces the glial scar formation after brain injury. Neuroscience, 2012. 224: p. 102-15.

15. Bokara KK, Kim JY, Lee YI, Yun K, Webster TJ, and Lee JE. Biocompatability of carbon nanotubes with stem cells to treat CNS injuries. Anat Cell Biol, 2013. 46(2): p. 85-92.

16. Walker PA, Aroom KR, Jimenez F, Shah SK, Harting MT, Gill BS, and Cox CS, Jr. Advances in progenitor cell therapy using scaffolding constructs for central nervous system injury. Stem Cell Rev, 2009. 5(3): p. 283-300.

17. Ito $\mathrm{Y}$, Hasuda $\mathrm{H}$, Kamitakahara M, Ohtsuki C, Tanihara M, Kang IK, and Kwon OH. $A$ composite of hydroxyapatite with electrospun biodegradable nanofibers as a tissue engineering material. J Biosci Bioeng, 2005. 100(1): p. 43-9.

18. Saracino GA, Cigognini D, Silva D, Caprini A, and Gelain F. Nanomaterials design and tests for neural tissue engineering. Chem Soc Rev, 2013. 42(1): p. 225-62.

19. Brown RA, Blunn GW, and Ejim OS. Preparation of orientated fibrous mats from fibronectin: composition and stability. Biomaterials, 1994. 15(6): p. 457-64.

20. Ejim OS, Blunn GW, and Brown RA. Production of artificial-orientated mats and strands from plasma fibronectin: a morphological study. Biomaterials, 1993. 14(10): p. 743-8.

21. Keilhoff G, Stang F, Wolf G, and Fansa H. Bio-compatibility of type I/III collagen matrix for peripheral nerve reconstruction. Biomaterials, 2003. 24(16): p. 2779-87.

22. Zhang W, Chen J, Tao J, Jiang Y, Hu C, Huang L, Ji J, and Ouyang HW. The use of type 1 collagen scaffold containing stromal cell-derived factor-1 to create a matrix environment conducive to partial-thickness cartilage defects repair. Biomaterials, 2013. 34(3): p. 713-23.

23. Martinez-Ramos C, Lainez S, Sancho F, Garcia Esparza MA, Planells-Cases R, Garcia Verdugo JM, Gomez Ribelles JL, Salmeron Sanchez M, Monleon Pradas M, Barcia JA, and Soria JM. Differentiation of postnatal neural stem cells into glia and functional neurons on laminin-coated polymeric substrates. Tissue Eng Part A, 2008. 14(8): p. 1365-75.

24. Soria JM, Martinez Ramos C, Salmeron Sanchez M, Benavent V, Campillo Fernandez A, Gomez Ribelles JL, Garcia Verdugo JM, Pradas MM, and Barcia JA. Survival and differentiation of embryonic neural explants on different biomaterials. J Biomed Mater Res A, 2006. 79(3): p. 495-502.

25. Martinez-Ramos C, Valles-Lluch A, Verdugo JM, Ribelles JL, Barcia Albacar JA, Orts $\mathrm{AB}$, Soria Lopez JM, and Pradas MM. Channeled scaffolds implanted in adult rat brain. J Biomed Mater Res A, 2012. 100(12): p. 3276-86.

26. Rodriguez Hernandez JC, Serrano Aroca A, Gomez Ribelles JL, and Pradas MM. Three-dimensional nanocomposite scaffolds with ordered cylindrical orthogonal pores. J Biomed Mater Res B Appl Biomater, 2008. 84(2): p. 541-9.

27. Más Estellés J, I. K, Rodríguez Hernández JC, Piotrowska A, and Monleón Pradas M. Mechanical properties of porous crosslinked poly(ethyl-acrylate) for tissue engineering. Journal of Materials Science, 2007. 42(20): p. 6.

28. Paxinos G and Watson C. The rat brain in stereotaxic coordinates. 1986, San Diego: Academic Press. 
29. Harting MT, Sloan LE, Jimenez F, Baumgartner J, and Cox CS, Jr. Subacute neural stem cell therapy for traumatic brain injury. J Surg Res, 2009. 153(2): p. 188-94.

30. Wallenquist U, Brannvall $\mathrm{K}$, Clausen F, Lewen A, Hillered L, and Forsberg-Nilsson K. Grafted neural progenitors migrate and form neurons after experimental traumatic brain injury. Restor Neurol Neurosci, 2009. 27(4): p. 323-34.

31. $\mathrm{Ma} \mathrm{H}, \mathrm{Yu}$ B, Kong L, Zhang Y, and Shi Y. Transplantation of neural stem cells enhances expression of synaptic protein and promotes functional recovery in a rat model of traumatic brain injury. Mol Med Rep, 2011. 4(5): p. 849-56.

32. Sun D, Gugliotta M, Rolfe A, Reid W, McQuiston AR, Hu W, and Young H. Sustained survival and maturation of adult neural stem/progenitor cells after transplantation into the injured brain. J Neurotrauma, 2011. 28(6): p. 961-72.

33. Doetsch F, Caille I, Lim DA, Garcia-Verdugo JM, and Alvarez-Buylla A. Subventricular zone astrocytes are neural stem cells in the adult mammalian brain. Cell, 1999. 97(6): p. 703-16.

34. Fuentealba LC, Obernier K, and Alvarez-Buylla A. Adult neural stem cells bridge their niche. Cell Stem Cell, 2012.10(6): p. 698-708.

35. Rice AC, Khaldi A, Harvey HB, Salman NJ, White F, Fillmore H, and Bullock MR. Proliferation and neuronal differentiation of mitotically active cells following traumatic brain injury. Exp Neurol, 2003. 183(2): p. 406-17.

36. Lee $\mathrm{C}$ and Agoston DV. Vascular endothelial growth factor is involved in mediating increased de novo hippocampal neurogenesis in response to traumatic brain injury. J Neurotrauma, 2010. 27(3): p. 541-53.

37. Sun D, Bullock MR, Altememi N, Zhou Z, Hagood S, Rolfe A, McGinn MJ, Hamm R, and Colello RJ. The effect of epidermal growth factor in the injured brain after trauma in rats. J Neurotrauma, 2010. 27(5): p. 923-38.

38. Amado S, Simoes MJ, Armada da Silva PA, Luis AL, Shirosaki Y, Lopes MA, Santos JD, Fregnan F, Gambarotta G, Raimondo S, Fornaro M, Veloso AP, Varejao AS, Mauricio AC, and Geuna S. Use of hybrid chitosan membranes and N1E-115 cells for promoting nerve regeneration in an axonotmesis rat model. Biomaterials, 2008. 29(33): p. 4409-19.

39. Verreck G, Chun I, Li Y, Kataria R, Zhang Q, Rosenblatt J, Decorte A, Heymans K, Adriaensen J, Bruining M, Van Remoortere M, Borghys H, Meert T, Peeters J, and Brewster ME. Preparation and physicochemical characterization of biodegradable nerve guides containing the nerve growth agent sabeluzole. Biomaterials, 2005. 26(11): p. 1307-15.

40. Park KI, Teng YD, and Snyder EY. The injured brain interacts reciprocally with neural stem cells supported by scaffolds to reconstitute lost tissue. Nat Biotechnol, 2002. 20(11): p. 1111-7.

41. Teng YD, Lavik EB, Qu X, Park KI, Ourednik J, Zurakowski D, Langer R, and Snyder EY. Functional recovery following traumatic spinal cord injury mediated by a unique polymer scaffold seeded with neural stem cells. Proc Natl Acad Sci U S A, 2002. 99(5): p. 3024-9. 


\section{FIGURES}
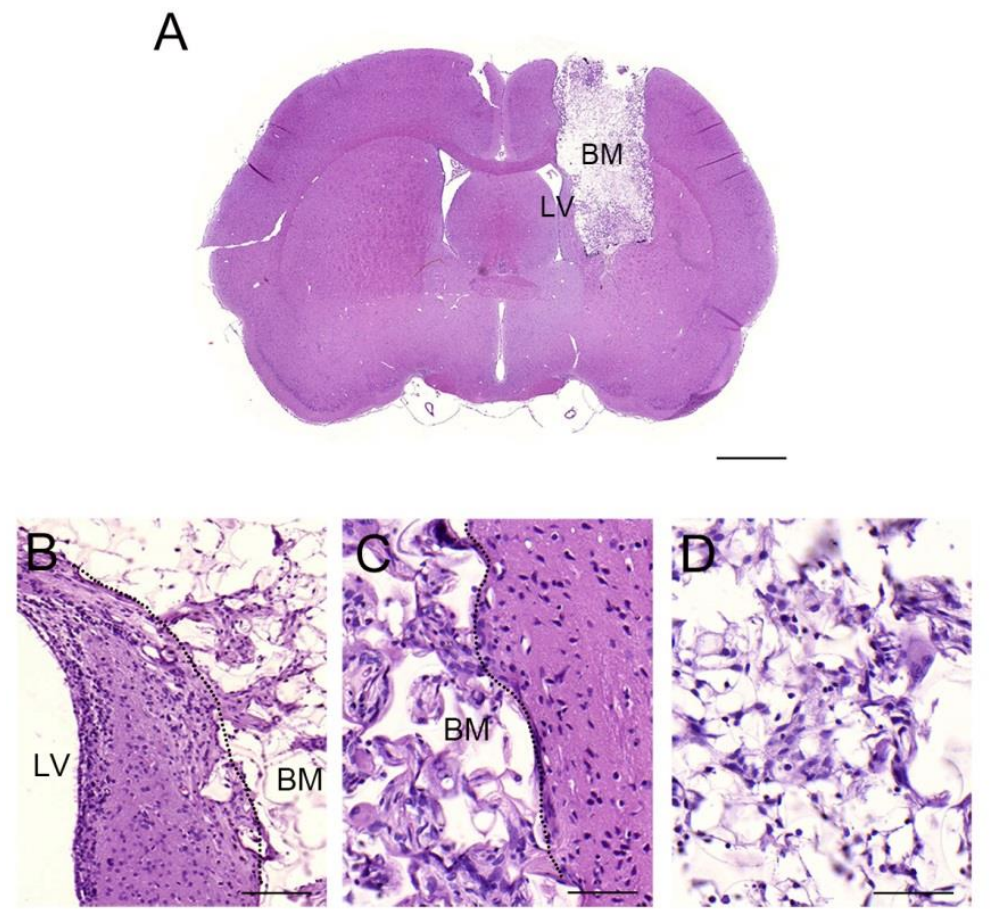

Figure 1. Histological characterisation of the implanted biomaterial and surrounding area shows the implantation of the scaffold and the colonization of cells.

A.Haematoxylin-eosin staining of a brain coronal section with BM. B. Image of the area close to the LV showing the insertion of the biomaterial respecting the integrity of the LV. C. Higher magnificaton image showing the continuity between the neural tissue and the biomaterial. D. View of the scaffold showing a high density of cells. The edge of the biomaterial is delimited by the dotted line. BM: biomaterial, LV: lateral ventricle. Scale bars: $500 \mu \mathrm{m}$ in $\mathrm{A}$, in $\mathrm{B} 100 \mu \mathrm{m}$ and $500 \mu \mathrm{m}$ in $\mathrm{C}$ and $\mathrm{D}$. 

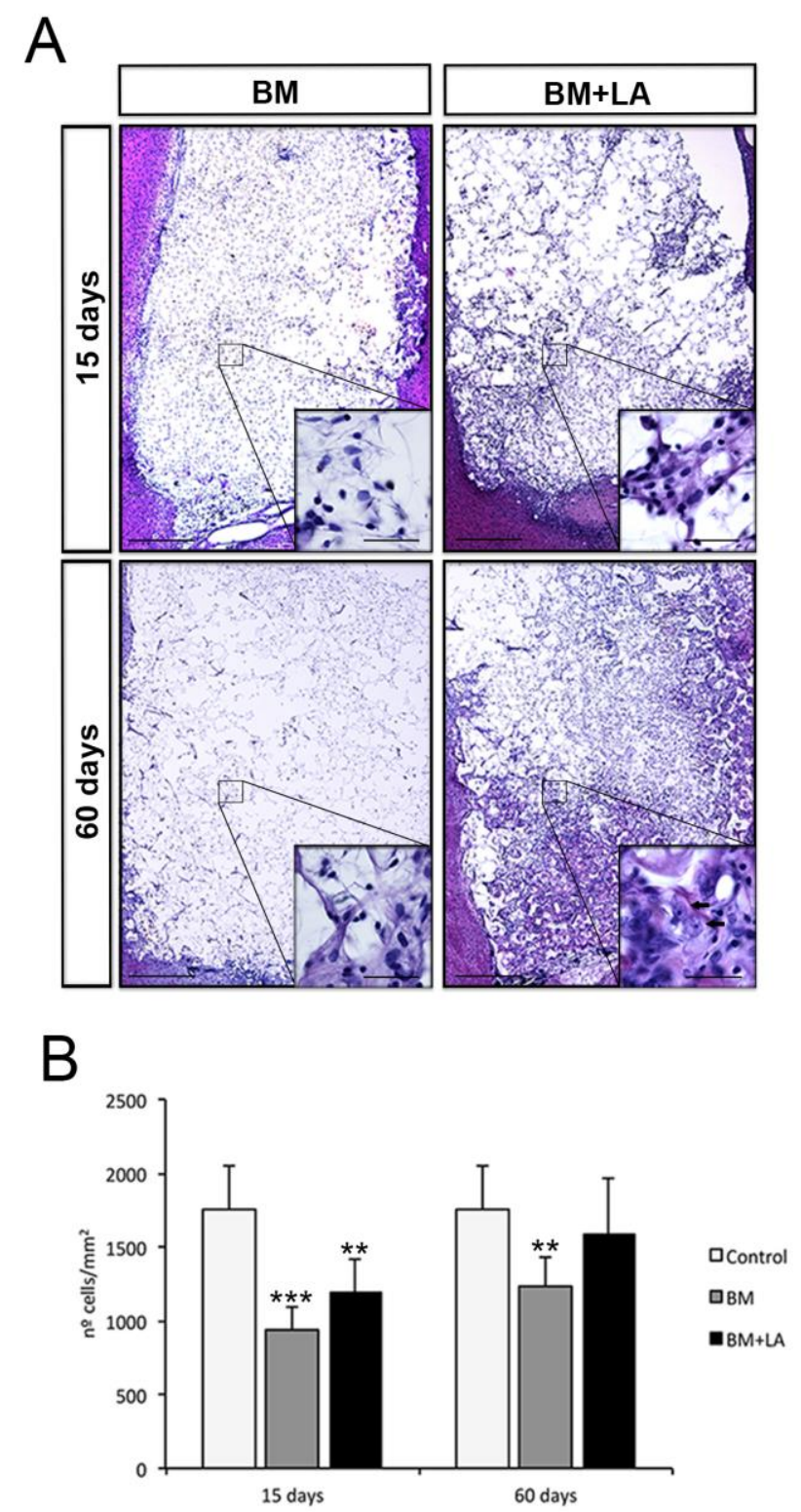

Figure 2. Cells are able to colonize and grow inside the biomaterial.

A. Images of the tissue inside the biomaterial where it is possible to appreciate a high number of cells and cytoplasmic extensions in LA treated animal. B. Cell density ( ${ }^{\circ}$ cells $/ \mathrm{mm}^{2}$ ) inside the biomaterial in the different experimental groups. BM: biomaterial, BM+LA: biomaterial and lipoic acid treatment. Scale bars: $200 \mu \mathrm{m}$ and $50 \mu \mathrm{m}$ in the expansions. . ${ }^{*} \mathrm{p}<0.05, * * \mathrm{p}<0.01, * * * \mathrm{p}<0.001$ 
A
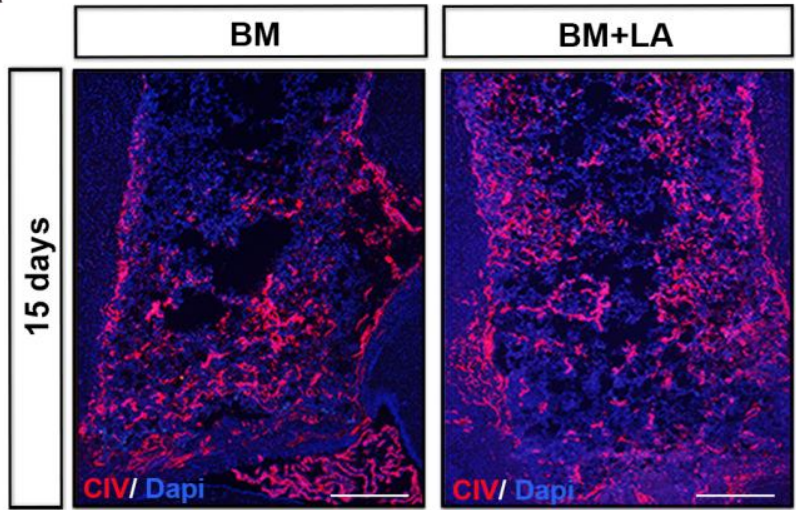

B
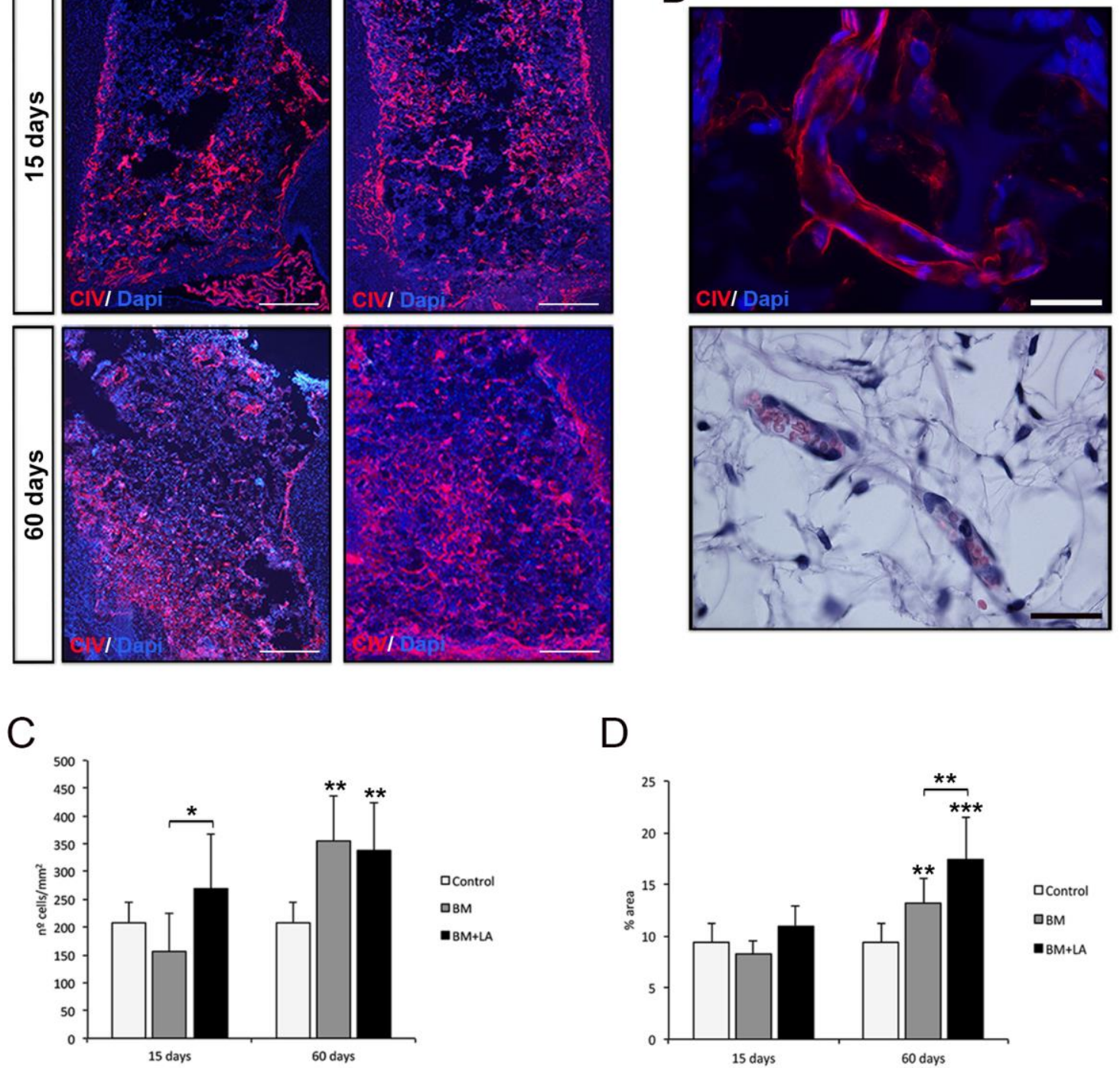

Figure 3. Immunofluorescence for Collagen IV shows blood vessels formation inside the biomaterial.

A. Immunofluorescence for collagen IV of blood vessels (red) inside the biomaterial at 15 and 60 days. Dapi was used to identify nuclei and biomaterial position. B. Top: Magnification image of a blood vessel well formed. Bottom: Magnification of a haematoxylin-eosin staining showing the functionality of the blood vessel. Scale bars: $200 \mu \mathrm{m}$ for A; $50 \mu \mathrm{m}$ for Top and $100 \mu \mathrm{m}$ for Bottom in B. C. Quantification of collagen positive cell density $\left(\mathrm{n}^{\mathrm{o}}\right.$ cells $/ \mathrm{mm}^{2}$ ) inside the biomaterial. D. Quantification of area occupied by blood vessels (\% area). Control: 
no injury or biomaterial, BM: biomaterial injured but untreated, BM+LA: injured, biomaterial and LA treatment. $* \mathrm{p}<0.05, * * \mathrm{p}<0.01, * * * \mathrm{p}<0.001$.
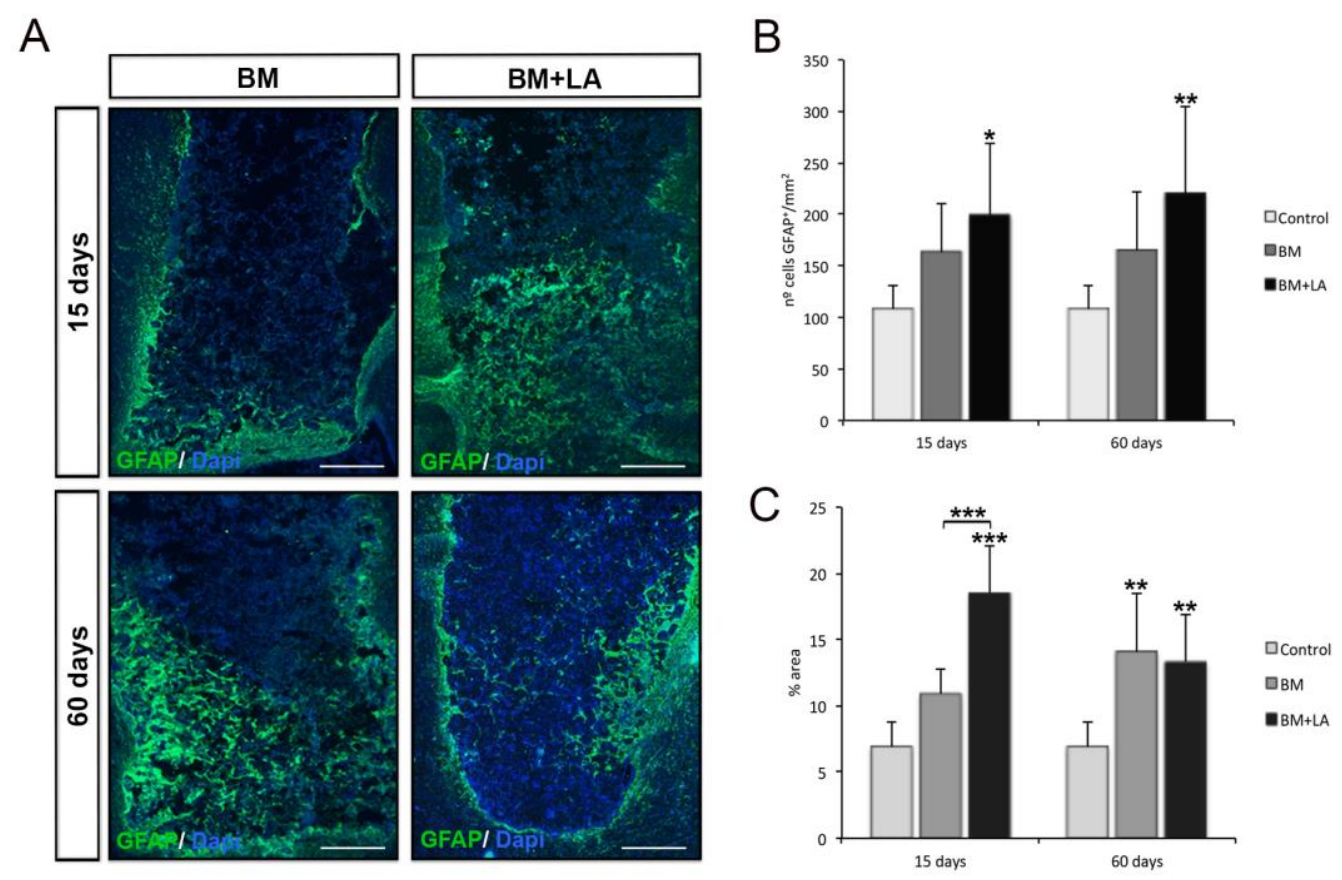

Figure 4. Immunofluorescence for GFAP shows the presence of astrocytes inside the

\section{biomaterial.}

A. Immunofluorescence for GFAP was done to identify astrocytes (green) inside the biomaterial at 15 and 60 days. Dapi was used to identify nuclei and biomaterial position. Scale bars: $200 \mu \mathrm{m}$. B. The graph represents the quantification of the density $\left(\mathrm{n}^{\mathrm{o}}\right.$ cells $\left./ \mathrm{mm}^{2}\right)$ of astroglial cells inside the biomaterial. C. Quantification of the area occupied by astrocytes (\% area). Control: no injury or biomaterial, BM: biomaterial injured but untreated, BM+LA: injured, biomaterial and LA treatment. $* \mathrm{p}<0.05,{ }^{*} \mathrm{p}<<0.01, * * * \mathrm{p}<0.001$ 

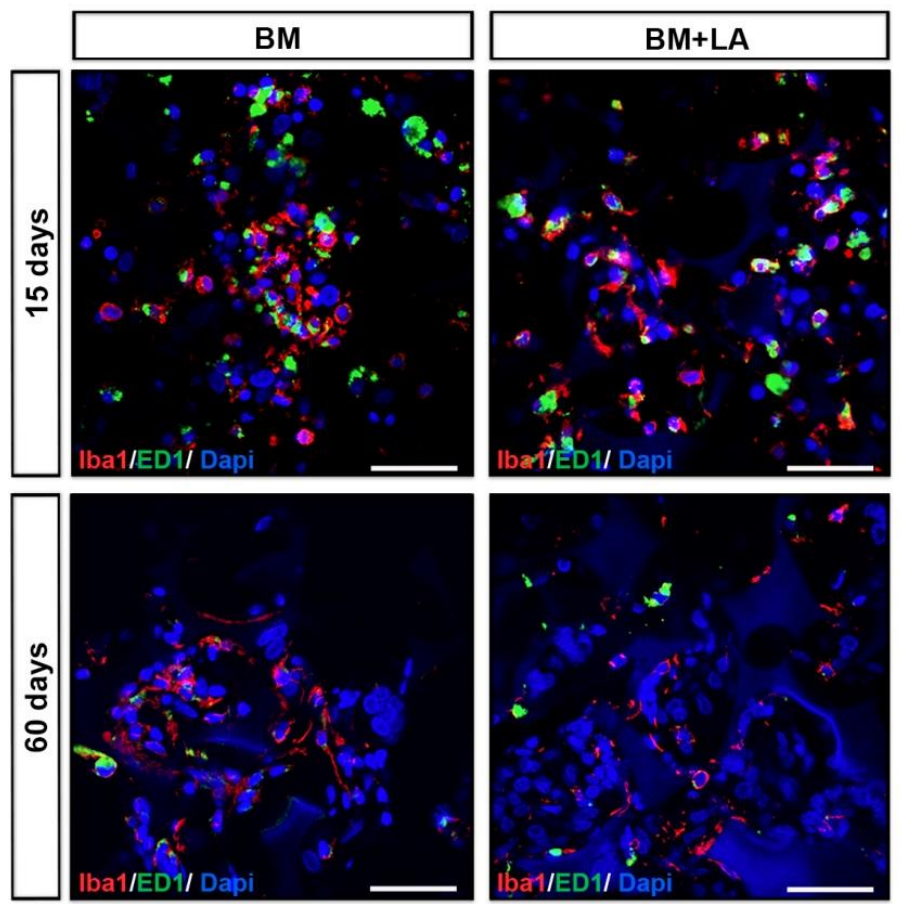

Figure 5. Microglial response is activated 15 days after brain injury.

Immunofluorescence for microglia cells (Iba1) in red and and for activated microglia/macrophagus (ED1) in green inside the biomaterial. Dapi was used to identify nuclei and biomaterial position. Scale bars: $50 \mu \mathrm{m}$.
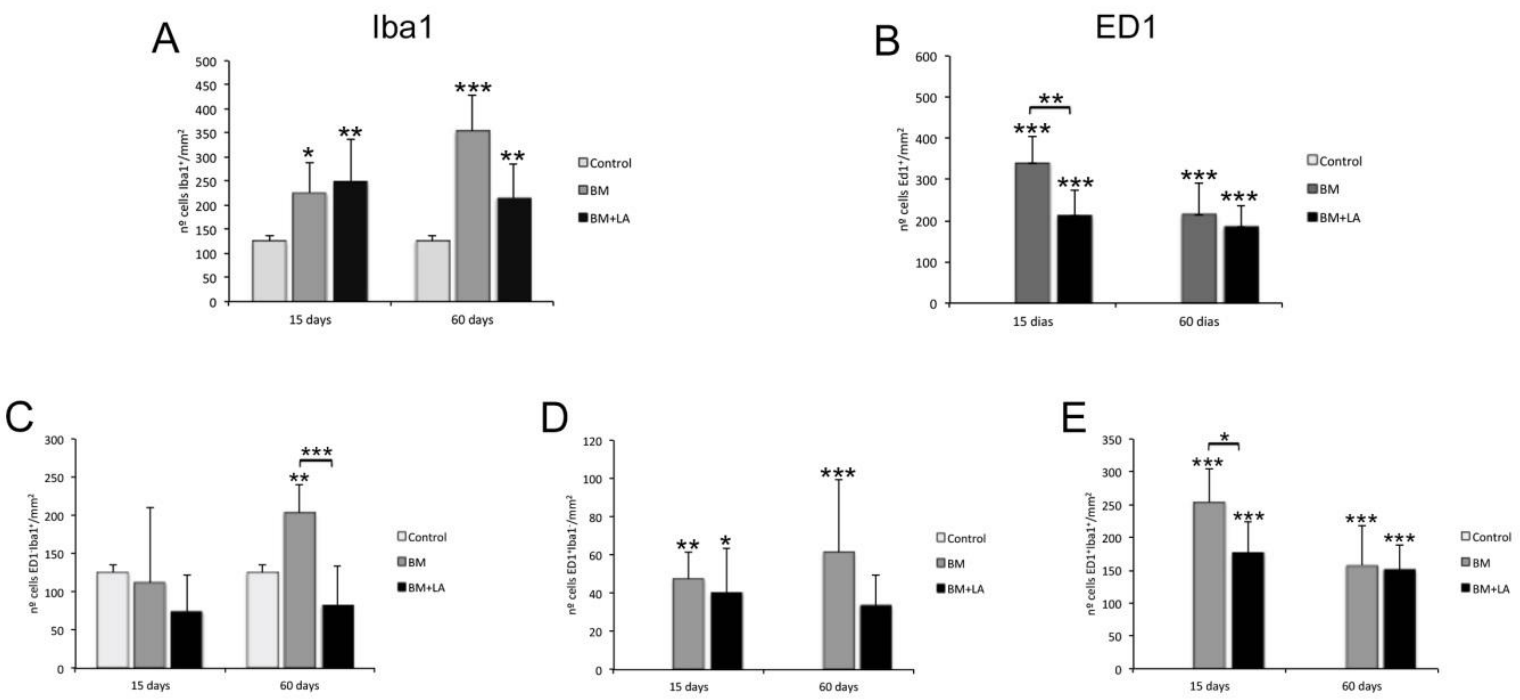

The

density of activated microglia/macrophagus cells $\left(\mathrm{ED} 1^{+}\right)$. C. Activated microglia $\left(\mathrm{Iba} 1^{+} \mathrm{ED} 1^{+}\right)$. D. Infiltrated macrophages $\left(\mathrm{Iba}^{-} \mathrm{ED} 1^{+}\right)$. E. Resting microglia $\left(\mathrm{Iba} 1^{+} \mathrm{ED} 1^{-}\right)$. Control: no injury or biomaterial, BM: biomaterial injured but untreated, BM+LA: injured, biomaterial and LA treatment. $* \mathrm{p}<0.05, * * \mathrm{p}<0.01, * * * \mathrm{p}<0.001$ 

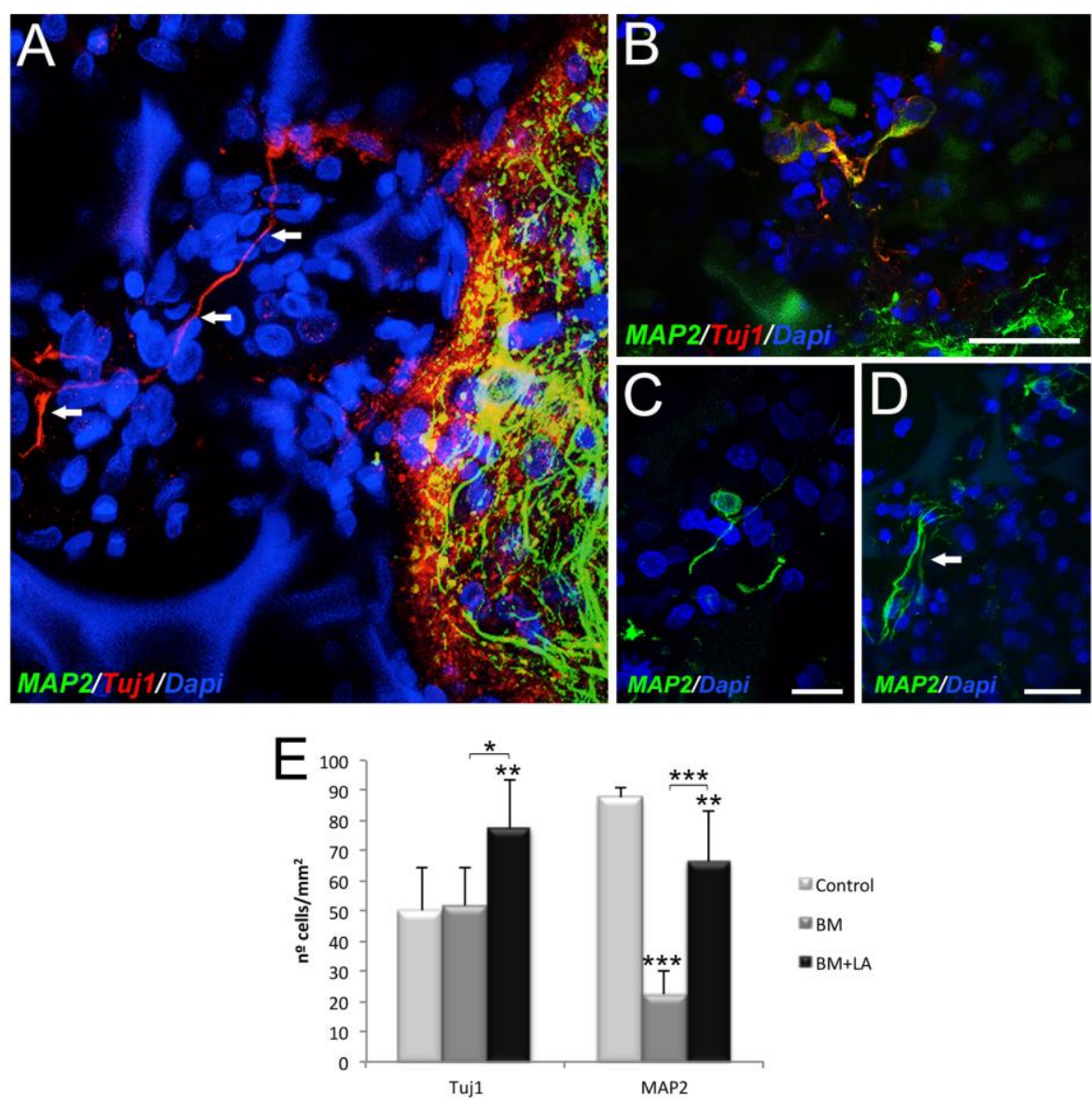

Figure 7. Immature and mature neurons extend their axons inside the scaffold.

Immunofluorescences for Tuj1 were done to identify immature neurons (red) and MAP2 were done to identify mature neurons (green). Dapi was used to identify nuclei and biomaterial position. A. Axons extending form the surrounding tissue to the biomaterial. B. Immature neurons expressing marker of mature neurons. C. Mature neuron. D. Axons of mature neurons. White arrows indicate the axons within the biomaterial. Scale bars: $100 \mu \mathrm{m}$ in A and B, 50 in C $\mu \mathrm{m}, 25 \mu \mathrm{m}$ in D. E. Neuronal density $\left(\mathrm{n}^{\mathrm{o}}\right.$ cells $\left./ \mathrm{mm}^{2}\right)$ inside the biomaterial of immature and mature neurons. Control: no injury or biomaterial, BM: biomaterial injured but untreated, BM+LA: injured, biomaterial and LA treatment. ${ }^{*} \mathrm{p}<0.05, * * \mathrm{p}<0.01, * * * \mathrm{p}<0.001$. 

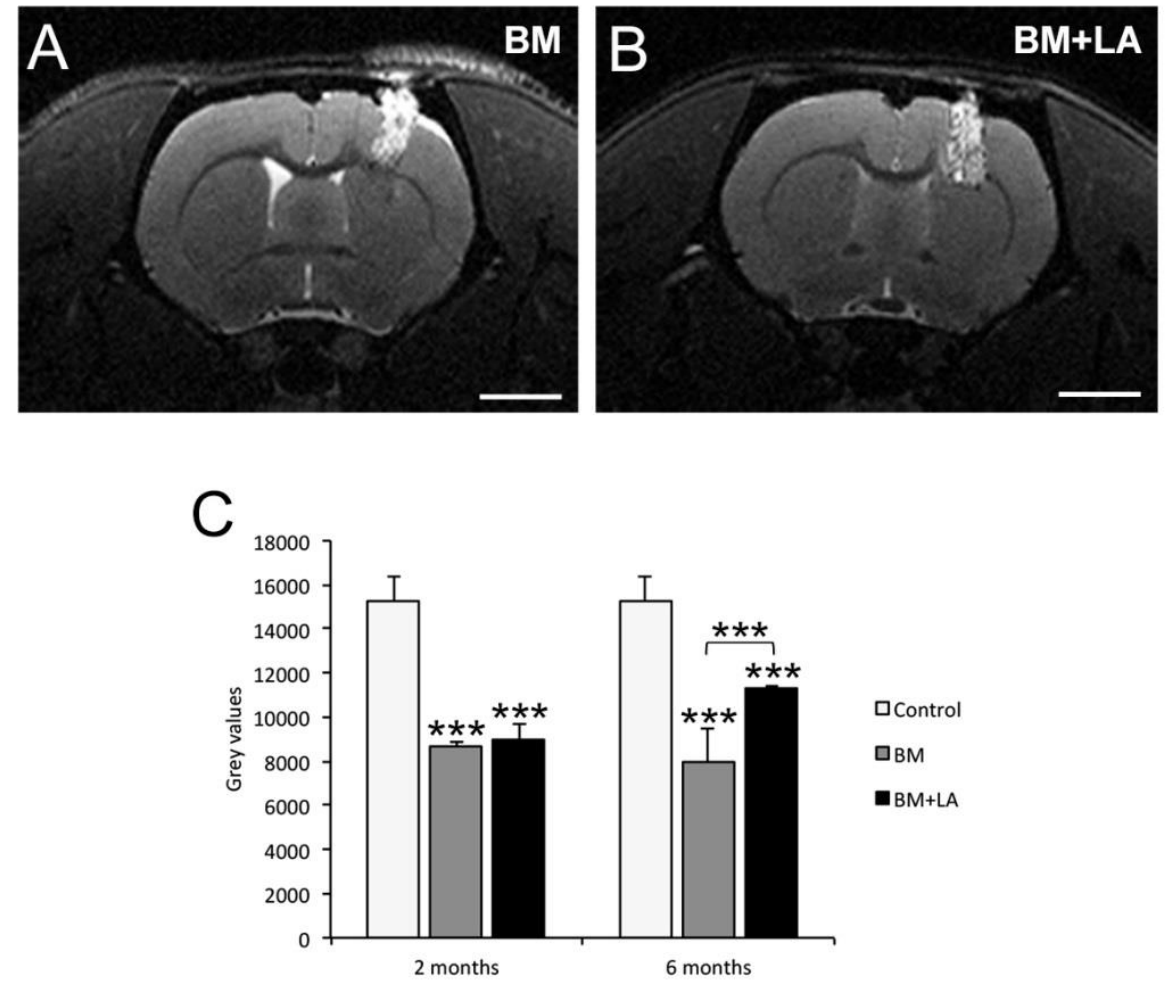

Figure 8. Magnetic resonance imaging shows an improvement in tissue restoration inside the scaffold.

Structural images T2 of untreated animals (A) and LA treated animals (B) were obtained 2 months after the brain injury. C. Quantification in grey values of the tissue inside the biomaterial at 2 and 6 months. Scale bars: $2 \mathrm{~mm}$. Control: no injury or biomaterial, BM: biomaterial injured but untreated, BM+LA: injured, biomaterial and LA treatment. $* * * \mathrm{p}<$ 0.001 .

\section{CAPTIONS}

